\title{
МГП И МЕЖДУНАРОДНЫЕ ВОЕННЫЕ ОПЕРАЦИИ ПО ПОДДЕРЖАНИЮ И ВОССТАНОВЛЕНИЮ MUPA
}

\section{Б.Р. Т у 3 М У Х А М Е Д О В*}

Проблема, заявленная в заголовке, во многом является terra incognita для отечественной доктрины международного права при том, что последняя уделяла немало внимания как МГП ${ }^{1}$, так и юридическим аспектам операций по поддержанию и восстановлению мира ${ }^{2}$. В то же время юристы разных стран, в частности, эксперты MKKK, уже относительно давно стали проявлять интерес К применению норм МГП в условиях операций по поддержанию мира ${ }^{3}$.

Современные многокомпонентные операции, осуществляемые начиная с первой половины 1990-х гг., и прогнозируемые операции требуют новых подходов с точки зрения МГП, и это вызов, который западная международно-правовая доктрина уже приняла 4 .

В первые годы существования ООН дебаты относительно места МГП в операциях Объединенных Наций “главным образом сводились К тому, применимо ли право, предназначенное для действия в условиях конфликтов между государствами, к тому, что считалось качественно иными военными операциями. Так, выдвигалось предположение о том, что даже если Объединенные Нации, осуществляя полномочия по Главе VII, начнут крупную наступательную военную операцию против агрессора, это будут действия правоохранительного органа, но не враждующей стороны и, соответственно, военные действия не будут носить характера войны"5. Дальнейшие события сделали эти дискуссии отвлеченными и несущественными. Стало ясно: реализация Главы VII Устава ООН так, как она задумывалась создателями Организации, - это дело в лучшем случае отдаленного будущего.

K ранним ОПМ в основном привлекались невооруженные военные наблюдатели или легковооруженные контингенты, и, характеризуя их с точки зрения МГП, можно согласиться с А. Бувье, который пишет, что в течение нескольких десятков лет вопрос о применимости МГП к вооруженным силам под флагом ООН "представлял в основном теоретический интерес: операции в сущности были немногочисленными, с очень ограниченным мандатом и практически исключали применение

* Кандидат юридических наук, доцент. Подробнее об авторе см. № 2 нашего журнала за 1996 г. 
силы; поэтому объективно ситуации, в которых могло или должно было применяться МГП, возникали редко"6. Тем не менее, персонал операций, его транспорт, по всей видимости, могли претендовать на защиту, предоставляемую Женевскими конвенциями и другими нормами МГП гражданским лицам и гражданским объектам.

Однако ООН не является “державой” по смыслу конвенций и не участвует в них, хотя именно эта Организация несет первоочередную ответственность за военнослужаших, выступающих от ее имени, под ее флагом, носят на своей форме соответствуюшие эмблемы и отличительные знаки. Означает ли это, что участники ОПМ лишаются защиты, предоставляемой Женевскими конвенциями? Или же такая защита предоставляется уже в силу того, что практически все государства, направляющие контингенты в состав сил, участвуют в Женевских конвенциях? Любопытно, что некоторые авторитетные исследователи ставили вопрос об участии ООН в Женевских конвенциях путем присоединения, посредством специального (третьего) дополнительного протокола, или же путем принятия Советом Безопасности или генеральной Ассамблеей декларации об обязательстве соблюдать конвенции ${ }^{7}$.

Появление в операциях нового поколения элементов принуждения, расширяюшего возможности применения оружия персоналом ООН как для самозащиты, так и в иных целях, например, для преодоления попыток воспрепятствовать выполнению их мандата, ставит новые вопросы. Например, становились ли военнослужащие $\mathrm{OOH}$ в бывшей Югославии комбатантами во время кратковременных эпизодов применения силы (авиации НАТО, действовавшей по заказу ООН), против участников конфликта, когда такое применение силы не вызвалось потребностями самозащиты? Положительный ответ на этот вопрос означал бы, что "голубые каски", участвуюшие в ОПМ с элементами принуждения, можно захватывать в плен и удерживать их в качестве военнопленных, соблюдая правила Женевских конвенций. А совместим ли статус военнослужашего Сил ООН со статусом военнопленного, ведь силы являются вспомогательным органом ООН, а, следовательно, на их персонал должны распространяться положения Конвенции о привилегиях и иммунитетах ООН 1946 г. и гарантии, предусмотренные для экспертов в командировках (статья VI).

Если исходить из того, что персонал ОПМ подпадает под защиту современного МГП, то в свете проведения большинства новейших операций в условиях немеждународных конфликтов неизбежно возникает вопрос: какой из двух дополнительных протоколов к Женевским конвенциям предоставляет такую зашиту - первый, касаюшийся международных вооруженных конфликтов, или второй, применяемый в условиях вооруженных конфликтов немеждународного характера? На первый взгляд, ответ может показаться очевидным: применимость протокола определяется характером конфликта и, если конфликт международный, применяется первый протокол, а если немеждународный - 
применяется второй. Однако в литературе высказывается точка зрения, в соответствии с которой “силы ООН имеют в определенной мере международный характер и что во внутреннем конфликте Организация Объединенных Наций принимает участие не с целью оказания помощи одной из сторон, а с целью выполнения резолюций, принятых Советом Безопасности в отношении всех участвующих в конфликте сторон, и было бы логичным, чтобы к этим вооруженным силам применялись нормы МГП, применяемые к международным вооруженным конфликтам"8.

Недавно принятая и еше не вступившая в силу Конвенция о безопасности персонала ООН и связанного с ней персонала 1994 г., непосредственно направленная на зашиту военного, полицейского и гражданского компонентов операций $\mathrm{OOH}$, не распространяется на принудительные меры, осуществляемые на основании Главы VII Устава, в которой персонал участвует в качестве комбатантов. Получается, что на предоставляемую ею защиту можно рассчитывать лишь при проведении достаточно ограниченной номенклатуры операций. В литературе приводятся аргументы в пользу такого подхода и против него, ках и свидетельства острых дискуссий, сопровождавших переговоры о заключении Конвенциия.

Отметим, что принятый 17 июля 1998 г. Статут Международного уголовного суда относит к числу деяний, подпадаюших под его юрисдикцию в качестве военных преступлений “умышленное нанесение ударов по персоналу, объектам, материалам, подразделениям или транспортным средствам, задействованным в оказании гуманитарной помощи или в миссии по поддержанию мира в соответствии с Уставом Организации Объединенных Наций, пока они имеют право на защиту, которой пользуются гражданские лица или гражданские объекты по международному праву вооруженных конфликтов" 10 (өыделено автором - Б. T.). Можно предвидеть затруднения с применением этих положений на практике в силу уже упомянутого многокомпонентного характера современных и прогнозируемых ОПМ, допускающих применение силы, значительно выходяшее за пределы самозашиты.

Вопрос о применении норм МГП встает в связи с операциями, проводимыми региональными организациями, такими, как НАТО и СНГ, которые, как и ООН, не являются участниками Женевских конвенций.

Еще одна проблема, требующая решения, - это возможная роль персонала ОПМ в обеспечении соблюдения норм МГП участниками конфликта. Нередки случаи, когда нарушения тех или иных норм случаются в присутствии персонала ООН. Например, весной 1995 г. в зоне ответственности Британского кавалерийского батальона Сил ООН в Боснии в непосредственной близости от линии фронта и от расположения механизированной роты батальона были замечены группы военнослужащих одной из сторон конфликта в головных уборах, 
имитируюшие голубые каски сил ООН. Приблизительно в то же время в Сараево местные военнослужашие, переодевшись в захваченное ранее обмундирование французского батальона, захватили контрольно-пропускной пункт, взяв в заложники нескольких французских военных из состава Сил ООН"1.

В первом эпизоде можно усмотреть нарушение части 2 статьи 38 Дополнительного протокола I к Женевским конвенциям, которой "запрещается использовать отличительную эмблему Организации Объединенных Наций, кроме как с разрешения этой Организации". Строго говоря, для того, чтобы квалифицировать эти действия как однозначно подпадающие под действие указанного положения, упомянутая группа военнослужащих должна была бы следовать под флагом ОOH, передвигаться на автомобилях с характерной белой окраской и ясно различимыми опознавательными знаками или хотя бы иметь на головных уборах соответствующие знаки или эмблемы. Однако следует учитывать все обстоятельства эпизода: как уже было сказано, он произошел вблизи линии фронта и там, где располагалось подразделение сил ООН. Другая сторона конфликта, наблюдая группу людей в голубых шлемах с некоторого удаления, вполне могла принять их за пользующиеся защитой персонал ООН. Отслеживая их движение и обнаружив, что они вливаются в боевые порядки противника, та сторона могла бы предпринять различные акции - от пропагандистских ("ООН воюет на стороне врага!") до насильственных (обстрел позиций сил ООН, захват персонала ООН в заложники).

На этот эпизод можно взглянуть сквозь призму части 1 статьи 39 того же протокола, которой "запрещается использовать в вооруженном конфликте флаги, военные эмблемы, воинские знаки различия или форменную одежду нейтральных государств или других государств, не являющихся сторонами, находяшимися в конфликте". Конечно, понятие "государство" не распространяется на ООН, однако приведенное положение Дополнительного протокола I, как представляется, вполне могло бы быть применено по аналогии или же на том основании, что силы ООН состояли из отдельных национальных подразделений государств, не участвующих в конфликте.

Действия, запрещенные частью 1 статьи 38 ни в коем случае не являются разрешенными военными хитростями, то есть действиями, направленными на то, чтобы "ввести противника в заблуждение или побудить его действовать опрометчиво” (часть 2 статьи 37 Дополнительного протокола I). И, как отмечено в Комментарии МККК к Дополнительным протоколам, “если такой способ введения в заблуждение вызывает у противника уверенность в существовании оснований для защиты, предоставляемой правом вооруженных конфликтов, он уже составляет акт вероломства".12 
Что касается вероломства, его элементы налицо во втором эпизоде. Напомним, что частью 1 статьи 37 Дополнительного протокола вероломство определяется как “действия, направленные на то, чтобы вызвать доверие противника и заставить его поверить, что он имеет право на защиту или обязан предоставить такую защиту согласно нормам международного права, применяемым в период вооруженных конфликтов, с целью обмана такого доверия". И далее в пункте “d” части 1 статьи 37 в качестве примера вероломства приводится "симулирование обладания статусом, предоставляющим защиту, путем использования знаков, эмблем или форменной одежды Организации Объединенных Наций, нейтральных государств или других государств, не являющихся сторонами, находяшимися в конфликте”.

Впрочем, может возникнуть вопрос о допустимости применения данного положения, поскольку Силы ООН в Боснии и Герцеговине не были стороной конфликта, а потому не могли считаться “противником" в смысле приведенного выше определения понятия "вероломства". Однако и в этом случае, как представляется, допустима аналогия. Кроме того, как отмечено в Комментарии МККК к Дополнительным протоколам, “ в том, что касается ООН, допустимо утверждать, что неправомерное использование ее знаков, эмблем или форменной одежды будет составлять акт вероломства в тех случаях, когда персонал ООН имеет статус нейтральной стороны или стороны, находящейся под защитой"13. Этот коммёнтарий основан на официальных протоколах дипломатической конференции 1974-77 гг., на которой вырабатывались протоколы, то есть с привлечением дополнительных средств толкования международного договора, как они определены в статье 32 Венской конвенции о праве международных договоров 1969 г.

Подобных эпизодов в истории операций ООН было немало. Здесь же в первом случае батальон ограничился сообщением в штаб сектора, во втором - была предпринята операция, целью которой было исключительно освобождение заложников, но не преследование нарушителей норм МГП.

Юридическая квалификация следующего эпизода несколько затруднена. Жилой квартал боснийского города в зоне ответственности автора этих строк подвергался артиллерийскому обстрелу, в ходе которого применялись боеприпасы, содержащие белый фосфор. Несколько гражданских лиц получили серьезные ожоги. Предположительно, это были дымовые боеприпасы, которые случайно или в результате преднамеренных манипуляций оказали ожоговое действие. Так или иначе, эти боеприпасы не подпадали под запрет, установленный Протоколом о запрешении или ограничении применения зажигательного оружия $\mathrm{k}$ Конвенции о запрещении некоторых видов обычного оружия 1981 г. Однако очевидно, что их применением были нарушены нормы Женевских конвенций, запрещающие применение методов и средств ведения 
боевых действий, причиняюших излишние страдания или повреждения. И вновь подразделение Сил $\mathrm{OOH}$ ограничилось извещением штаба сектора об инциденте, а затем туда же направило осколки снарядов для квалифицированной экспертизы.

Итак, должен ли военный персонал ООН обеспечивать соблюдение норм МГП сторонами конфликта? Когда автор этих строк обратился с этим вопросом к участникам конференции, собравшей весной 1998 г. в канадском городе Виктории руководство военно-юридических служб государств Азиатско-Тихоокеанского региона, ответом ему был сдержанный ропот, кто-то даже вполне внятно произнес: "Можно подумать, что им больше нечего делать".

Однако это придется делать, если таковым будет предписание мандата на проведение операции. По мнению К. Гринвуда, "Совет Безопасности вправе, а в нынешних условиях такая возможность реальна, учредить операцию со специальным гуманитарным мандатом или же с таким мандатом, который будет включать обязанность обеспечивать соблюдение враждуюшими сторонами норм МГП". ${ }^{14}$ Если же мандат не будет содержать такого предписания, то мо:но предположить, что национальные контингенты, из которых состоят силы ООН, допустимо рассматривать в качестве инструмента обеспечения исполнения обязательства, которое их государства приняли на себя в соответствии со статьей 1 обшей для всех четырех Женевских конвенций. В соответствии с нею “Высокие Договариваюшиеся Стороны обязуются при любых обстоятельствах соблюдать и заставлять соблюдать настоящую конвенцию" (выделено автором - Б. Т.). По мнению авторов комментария MKKК к Женевским конвенциям, "если государство не выполняет своих обязательств, каждая из прочих Договаривающихся Сторон (нейтральная, союзная или вражеская) должна стремиться к тому, чтобы вернуть ее на путь уважения Конвенции... Государства-участники не должны ограничиваться односторонним соблюдением ее положений, им следует делать все, что в их власти, чтс.бы обеспечить ее всеобщее соблюдение" 15 .

Вопросы применения МГП в условиях ОПМ заслуживают специального внимания с учетом особенностей операций и статуса принимающего в них участие персонала. Речь должна идти как о совершенствовании правового регулирования, так и о подготовке персонала и усилении юридической службы будуших операций.

Подготовка персонала - важная и применительно к России далекая от решения проблема. С одной стороны, действующие документы предписывают, чтобы все военнослужашие, вне зависимости от того, участвуют они в международных военных операциях или нет, соблюдали 
нормы МГП. Так, Устав Внутренней службы Вооруженных Сил РФ, утвержденный Указом Президента РФ от 14 декабря 1993 г., обязывает их "Знать и неукоснительно соблюдать международные правила ведения военных действий, обращения с ранеными, больными, лицами, потерпевшими кораблекрушение, и гражданским населением в районе боевых действий, а также с военнопленными" 16 . Ранее, после того, как СССР ратифицировал Дополнительные протоколы к Женевским конвенциям, Министром обороны СССР был издан Приказ № 75 от 16 февраля 1990 г. ${ }^{17}$, которым как конвенции, так и протоколы объявлялись к исполнению в Вооруженных силах СССР. К приказу наряду с текстами указанных договоров прилагалось и Руководство по применению Вооруженными Силами СССР норм международного гуманитарного права ${ }^{18}$. Главным управлением международного военного сотрудничества Министерства обороны РФ подготовлен также специальный документ для российских военнослужащих, участвуюших в международных военных операциях ООН. В нем упоминаются основные источники МГП и на их основе кратко характеризуется статус воинского персонала международных операций ${ }^{19}$. А вот в другом специальном документе Наставлении по подготовке и проведению операций по поддержанию мира в СНГ - сказано, что личный состав Коллективных сил по поддержанию мира должен знать лишь “основы международного права" 20 .

С другой стороны, практическая работа по просвещению военнослужаших относительно МГП вообще и его применения в условиях международных военных операций - в частности, далека от совершенства. В учебной программе курсов военных наблюдателей ООН при Общевойсковой академии Вооруженных Сил РФ из 144 часов на изучение МГП отводится 3 часа ${ }^{21}$. На состоявшейся 18-19 мая 1999 г. научно-практической конференции “Правовые основы применения вооруженных сил в XXI веке" приводились такие цифры: в Академии Генерального штаба Вооруженных Сил РФ в настоящее время на освоение всех правсвых дисциплин отводится 12-16 часов и около трети этого времени приходится на изучение МГП.

Я далек от того, чтобы предлагать увеличить объем преподавания МГП в ущерб прикладным военным дисциплинам, речь должна идти хотя бы о том, чтобы эффективнее использовать скудные часы, выделяемые на его изучение, совмещать освоение МГП с тактической подготовкой, основами боевого применения вооруженных сил, чтобы правовые нормы не воспринимались абстрактно, а "привязывались" к конкретным ситуациям.

Ограниченный объем данной статьи позволил лишь обозначить отдельные аспекты проблемы и представить читателям некоторые из 
известньх автору документаљньх и литературньх источников. Представляется, даже это является достаточным свидетельством актуальности проблемы и аргументов в пользу ее дальнейшей разработки.

1 Для целей данной статьи под МГП будет пониматься "категория норм международного права, имеюцих целью гуманизацию вооруженных конфликтов." - Международное право: Учебник. Изд. 2-е, доп. и перераб. Отв. Ред. Ю. М. Колосов, В. И. Кузнецов. М., 1998, с. 402.

2 Для целей данной статьи под операциями по поддержанию и восстановлению мира будут пониматъся операции с военным компонентом, учрежденные уполномоченньпм на то органом ООН, действующим на основании Главы VI и/или VII Устава ООН и осуществлемые под общим командованием и оперативным руководством Организации.

${ }^{3}$ Cм., например: Yves Sandoz. The Application of Humanitarian Law by the Armed Forces of the United Nations Organization. - International Review of the Red Cross, No. 206, 1978, p. 274-284; Dietrich Schindler. United Nations Forces and Intemational Humanitarian Law. - In: Studies and Essays on International Humanitarian Law and Red Cross Principles in Honour of Jean Pictet. The Hague, 1984, p. $521-530$.

${ }^{4}$ Cм., например: Umesh Palwankar. Applicability of International Humanitarian Law to United Nations Peacekeeping Forces. - International Review of the Red Cross, No. 295, 1993, p. 227-240; Christopher Greenwood.International Humanitarian Law and United Nations Military Operations. - Yearbook of International Humanitarian Law, Vol. 1, 1998, p. 3-34; Eric David. Principes de droit des conflits armes. Deuxieme editon. Bruxelles 1999, pp. 140-146, 184-195.

${ }^{5}$ Greenwood, op. cit., at 4.

${ }^{6}$ Антуан Бувье. Конвенция о безопасности персонала Организации Объединенньх Наций и связанного с ней персонала: изложение и анализ. - Международный журнал Красното Креста, № 7, 1995, с. 792-793.

${ }^{7}$ Schindler, op. cit., p. 529-530.

${ }^{8}$ А. Бувье, ук. соч., с. 795.

${ }^{9}$ См. А. Бувье, ук. соч., с. 799-806; Mahnoush H. Arsanjani. Defending the Blue Helmets: Protection of United Nations Personnel. - In: The United Nations and International Humanitarian Law. Actes du Colloque international... Paris, 1995, p. 115-147; Evan N. Bloom. Protecting Peacekeepers: The Convention on the Safety of United Nations and Associated Personnel, AJIL Vol. 89:612 1995.

10 Подпункт 'iii' общий для пунктов 'b' и 'e' части 2 статъи 8 Статута Международного уголовного суда. - Док. ООН А/CONF. 183/9, p. 8, 11.

${ }^{11}$ Первый эпизод произошел в зоне ответственности автора в период его работы в составе Сил ООН в Боснии и Герцеговине, о втором ему было рассказано полковником запаса А. В. Демуренко, бывшим начальником штаба сектора "Сараево" Сил ООН.

12 Commentary on the Additional Protocols of 8 June 1977 to the Geneva Conventions of 12 August 1949. Eds. Yves Sandoz e. a. Geneva 1987, at 441.

${ }^{13}$ Id., at 439. 
14 Greenwood, op. cit. at. 32.

15 Commentary, III Geneva Convention Relative to the Treatment of Prisoners of War. Ed. Jean S. Pictet. Geneva, 1960, at 18.

${ }^{16}$ Собрание актов Президента и Правительства РФ, 20 декабря 1993, № 51, cT. 4931 .

${ }^{17}$ См.: Приказ Министра обороны СССР № 75 об объявлении Женевских конвенций о защите жертв войны от 12 августа 1949 года и Дополнительных протоколов к ним. М., Воениздат, 1990. Приказ остается в силе для Вооруженных Сил РФ.

18 В настоящее время военно-юридическая служба Вооруженньх Сил РФ завершает работу над всеобъемлюшим наставлением по правовой работе в ВС РФ, в которое отдельной главой войдут указания по применению норм МГП.

19 Руководство по действиям подразделений Вооруженных Сил Российской Федерации в составе войск ООН. М., ВТИИ, 1995, с. 10.

${ }^{20}$ Наставление по подготовке и проведению операций по поддержанию мира в Содружестве Независимых Государств. М.: Штаб по координации военного сотрудничества государств-участников СНГ, 1997, с. 19

21 По состоянию на начало 1998 г., когда курсы военных наблюдателей ООН еще входили в состав 1-х Высших офицерских курсов “Выстрел" имени Маршала Советского Союза Б. М. Шапошникова.

\title{
МЕЖДУНАРОДНЫЙ КОМИТЕТ КРАСНОГО КРЕСТА КАК ХРАНИТЕЛЬ МГП*
}

\author{
Ив С А Н Д О**
}

\section{Вступление}

Международный Комитет Красного Креста (МKKК) прежде всего известен проводимыми им во всем мире операциями помощи жертвам вооруженных конфликтов и ситуаций напряженности внутри страны.

Менее известна его роль “хранителя" международного гуманитарного права - права, применяемого во время вооруженных конфликтов. Эта сложная функция тесно связана с основанием МKKK. Впоследст-

* Статья написана Ивом Сандо для сборника "Mélanges Sahovic", опубликованном в "Yugoslav Review of International Law" в 1996 г.

** Директор Управления международного права и политики MKKК 